\title{
Avaliação da eficácia da homeopatia e fitoterapia no tratamento da papilomatose cutânea bovina
}

\section{Appraisal of efficiency of homeopathy and herbal therapy in the treatment of bovine cutaneous papillomatosis}

\author{
Rachel Siqueira de Queiroz Simões Marins, ${ }^{*}$ Carlos Eurico Pires Ferreira Travassos, ${ }^{* *}$ \\ Sílvia Regina Ferreira Gonçalves Pereira, ${ }^{* *}$ Maria Angélica Vieira da Costa Pereira, ${ }^{* *}$ Luis Fernando Pereira Vieira ${ }^{* * *}$
}

\begin{abstract}
Resumo
No presente trabalho foram utilizados 54 bovinos, mestiços, portadores da papilomatose plana e/ou pedunculada, de ambos os sexos e com idade variando entre 1 e 7 anos. Os animais foram divididos aleatoriamente em três grupos, com 18 bovinos cada. O Grupo 1 não recebeu nenhum tipo de tratamento (grupo controle). O Grupo 2 foi constituído pelos animais tratados homeopaticamente. O Grupo 3 foi constituído pelos animais que receberam tratamento fitoterápico. Os resultados obtidos demonstraram que os tratamentos homeopático e fitoterápico foram eficazes na cura da papilomatose cutânea bovina.
\end{abstract}

Palavras-chave: bovinos, homeopatia, fitoterapia, papilomatose.

\begin{abstract}
In the present work were utilizaded 54 bovines, half-breed, carried of sessile and/or pedunculated papillomas, of both sexes and with age varying among 1 to 7 years. The animals were divided randomly in 3 groups with 18 bovines each. The first group didn't received none treatment (control group). The second group was constituted for animals treated homeopathicaly. The third group was constituted for animals that received herbal therapy. The results obtained demonstrated that the homeopathic and herbal therapic treatments showed efficacious in the cure of bovine cutaneous papillomatosis.
\end{abstract}

Keywords: bovines, homeopathy, herbal fitoteraphy, pappillomatosis

\section{Introdução}

As terapias alternativas na medicina veterinária vêm crescendo a cada ano, principalmente pela ausência de resíduos tóxicos nos produtos de origem animal, tornando-se uma exigência terapêutica para a manutenção da saúde das criações da pecuária orgânica (Benez, 2002). A homeopatia tem como princípio básico a aplicação da "lei do semelhante" (Similia Similibus curantur) e foi introduzida em animais por volta de 1823 por Joseph Wilhelm Lux (Benites, 1999; Benez, 2002). Essa terapêutica oferece inúmeros benefícios aos pacientes tratados com doses mínimas, sendo seus efeitos colaterais praticamente irrisórios, enquanto a fitoterapia baseia-se no extrato bruto da planta (Morooka, 2002).

A papilomatose bovina é uma enfermidade infectocontagiosa, crônica, de caráter tumoral classificada na medicina homeopática como sicose, isto é, afecção geral permanente do organismo, que se manifesta por moléstia do epitélio escamoso queratinizado (pele) e não queratinizado (mucosas), no qual o medicamento de escolha antisicótico é a Thuya occidentalis (Benez et al., 2002).
A papilomatose é causada por um vírus DNA pertencente à família Papillomaviridae, gênero Papillomavirus e é descrita por Hahnemann como a "doença da verruga do figo", daí vulgarmente ser conhecida como figueira (Benites e Melville, 2003). A doença tem distribuição mundial. A morbidade apresenta-se bastante variável e a letalidade relativamente baixa. Não há predileção por sexo ou raça, entretanto, a doença é mais comum em animais com idade inferior a dois anos (Corrêa e Corrêa, 1992). Em cerca de $85 \%$ dos casos, a doença tem característica autolimitante, apresentando regressão espontânea com o desaparecimento das lesões (Murphy et al., 1999). Com o intuito de aplicar a prática da terapia alternativa no campo, este estudo buscou comparar a eficácia da homeopatia e fitoterapia no tratamento da papilomatose cutânea bovina.

\section{Material e métodos}

Utilizou-se um total de 54 bovinos mestiços, portadores da papilomatose plana e/ou pedunculada, de ambos os sexos e com idade variando entre 1 e 7 anos, alguns com história de

* Curso de Pós-Graduação em Produção Animal, UENF, e-mail: rsqsimoes@bol.com.br

** Laboratório de Sanidade Animal, Centro de Ciências e Tecnologias Agropecuárias, Universidade Estadual do Norte Fluminense Darcy Ribeiro, Av. Alberto Lamego, 2000 - CEP 28013-600, Campos dos Goytacazes, RJ.

*** Iniciação Científica do CNPq. 
papilomatose disseminada pelo corpo há mais de 10 meses, tendo sido tratados com medicamentos alopáticos e autohemoterapia sem sucesso há mais de seis meses.

Os animais foram divididos aleatoriamente em três grupos com 18 bovinos cada. O Grupo 1 não recebeu nenhum tipo de tratamento (grupo controle). O Grupo 2 foi constituído pelos animais que receberam tratamento homeopático com 3 doses de Thuya occidentalis na dinamização milesimal pela via oral com intervalo de 30 dias entre as aplicações no volume de $20 \mathrm{~mL}, 15 \mathrm{~mL}$ e $10 \mathrm{~mL}$, respectivamente. O Grupo 3 foi constituído pelos animais que receberam tratamento fitoterápico com tintura mãe de Thuya occidentalis através de pulverizações, com o auxílio de bomba pulverizadora no local das lesões totalizando três doses com intervalo de 30 dias entre as aplicações. A apresentação conjunta dos animais portadores de tumorações benignas encontra-se ilustrada nas Figura 1.

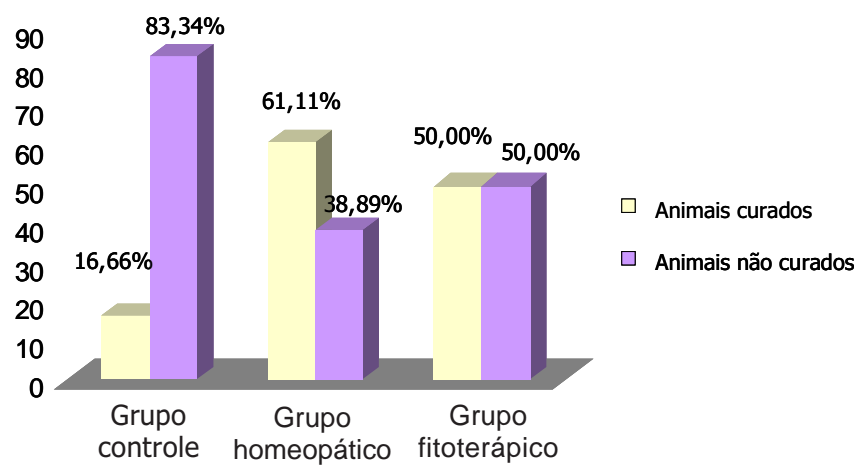

Figura 2: Representação gráfica da prevalência dos animais tratados e não tratados de acordo com os grupos - Grupo 1 (animais controle); Grupo 2 (animais tratados com homeopatia); Grupo 3 (animais tratados com fitoterapia).
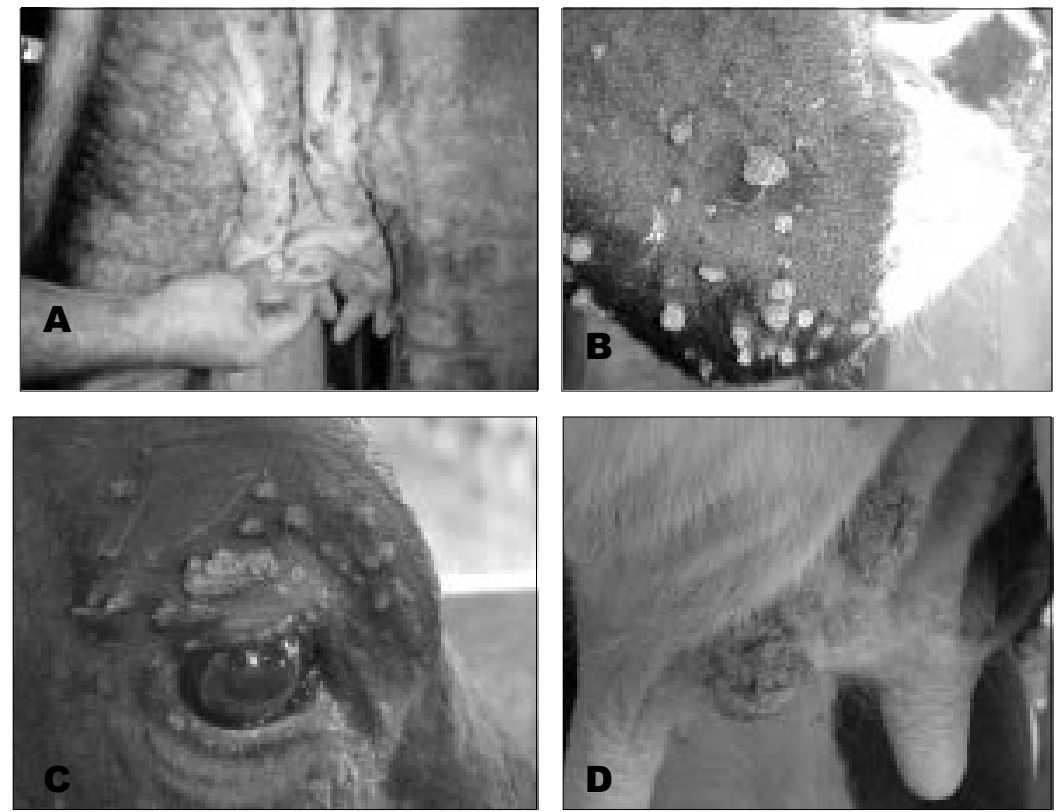

Figura 1: Imagens fotográficas de animais portadores de papilomas em diversas regiões corpóreas dos bovinos. Na foto $\mathrm{A}$, observam-se múltiplos papilomas achatados, de aspecto circunscrito localizados no úbere e nos membros posteriores de um bovino fêmea. Em B, nota-se a presença de pólipos de protuberância elevada apresentando coloração escura acinzentada, localizados no focinho. Em C, observam-se tumorações papilomatosas de aspecto irregular situadas ao redor dos olhos. Em D, verrugas de coloração rósea, medindo poucos centímetros de diâmetro, são visualizados no úbere.

A avaliação da eficácia do tratamento foi realizada mediante um sistema de escore de 0 a 6: ausência de regressão dos papilomas (escore 0 ), regressão mínima (escore 2), média (escore 4) e máxima (escore 6). Os animais foram observados durante um período de 90 dias.

\section{Resultados e discussão}

Dos 18 animais do Grupo 1 (grupo controle), três apresentaram regressão espontânea mínima (escore 2), correspondendo a 16,66\%. Em 61,11\% (11/18) dos animais do Grupo 2 e em 50,00\% (9/18) dos animais do Grupo 3, apresentaram recuperação completa (escore 6) ao final de 90 dias de observação, melhor representada na Figura 2.
Resultados satisfatórios na utilização da Thuya occidentalis no tratamento da papilomatose cutânea bovina foram encontrados por Rai et al. (1991) e Prakash (1993). Ambos os autores administraram diariamente de 8 a 10 glóbulos de Thuya occidentalis na dinamização 200 pela via oral durante um período de 21 dias. Contudo, torna-se difícil comparar os resultados encontrados neste experimento, devido à inexistência de dados na literatura homeopática para o tratamento da papilomatose bovina na formulação de solução aquosa administrada pela via oral, tampouco pelo fato deste trabalho ser pioneiro no tratamento fitoterápico dessa enfermidade.

Com isso, o tratamento utilizado no grupo de animais escolhido, apesar de não ter promovido recuperação total, por se tratar da papilomatose na forma plana em mais de $90 \%$, aparentemente contribuiu para diminuir o número de papilomas em 11 bovinos do Grupo 2 e em nove bovinos do Grupo 3. Contudo, resultados desfavoráveis no tratamento da papilomatose plana condiz com Hama et al. (1988), ao se referir ao uso de drogas alopáticas e tratamentos convencionais, pelo fato de a forma plana, achatada e aderida à pele, apresentar uma menor resposta a qualquer tipo de terapêutica.

A Thuya occidentalis é extremamente utilizada na medicina humana para o tratamento de verrugas e condilomas na pele e nas mucosas, sendo que os pacientes obtêm recuperação após dois a seis meses de uso contínuo do medicamento. Em comparação com a espécie bovina, a recuperação se dá mais rapidamente, cerca de um mês, dependendo da posologia, o que indica que o tratamento homeopático e fitoterápico mostraram-se eficazes e, dessa forma, podem ser preconizados para a enfermidade de curso crônico apresentando bons resultados, além de serem econômicos e de fácil aplicação, não interferindo no manejo de rotina das propriedades. 


\section{Referências}

BENEZ, S.M. Manual de homeopatia veterinária: indicações clínicas e patológicas - teoria e prática. São Paulo: Robe Editorial, 594 p., 2002. BENITES, N.R. A homeopatia através dos séculos. Revista Clínica Veterinária, ano IV, n. 20, p. 36, 1999.

BENITES, N.R., MELVILLE, P.A. Tratamento homeopático de papilomatose canina. Revista Clínica Veterinária, ano VIII, n. 44, p.19-20, 2003.

CORRÊA, W.M., CORRÊA, C.C.M. Enfermidades infecciosas dos mamíferos domésticos. 2. ed. Rio de Janeiro: Medsi, 843 p., 1992.

HAMA, C., MATSUMOT, T., FRANCESCHINI, P.H. Papilomatose bovina: avaliação clínica de diferentes produtos usados no controle e tratamento. Ciência Veterinária, v. 2, p. 14-15, 1988.
MOROOKA, C. Homeopatia na clínica veterinária. http://www.anclivepasp.org.brem 30/3/2003.

MURPHY, F.A., GIBSS, P.J., HORZINEK, M.C., STUDDERT, M.J. Veterinary Virology, 3. ed., Academic Press, 629 p. 1999.

PRAKASH, R. Homeopathic drug treatment of bovine cutaneous papillomatosis in a heifer: a case report. Indian Veterinary Journal, v. 70, n. 11, p. 1055-1056, 1993.

RAI, R.B., SAHA, P., SRIVASTAVA, N., NAGRAJAN, V. Bovine papillomatosis in Andaman and Nicobar. Indian Veterinary Journal, v. 15, p. 71-72, 1991. 